\title{
Influence of Obesity on the Metabolism of Apolipoprotein B in Humans
}

Genshi Egusa, William F. Beltz, Scott M. Grundy, and Barbara V. Howard

Phoenix Clinical Research Section, National Institute of Arthritis, Diabetes, Digestive, and Kidney Diseases, National Institutes of Health, Phoenix, Arizona 85016

\begin{abstract}
The influence of obesity on the metabolism of apolipoprotein B (apo B) in very low density lipoprotein (VLDL), intermediate density lipoprotein (IDL), and low density lipoprotein (LDL) was investigated in nine obese and seven nonobese Pima Indian men. Kinetics of VLDL-apo B (VLDL-B), VLDL-triglycerides, IDL-B and LDL-B were studied after injection of autologous ${ }^{131}$ I-VLDL, [ $\left.{ }^{3} \mathrm{H}\right]$ glycerol, and autologous ${ }^{125}$ I-LDL. Specific activities were measured in apo $B$ isolated from all lipoprotein fractions and in triglyceride isolated from VLDL. Transport rates and fractional catabolic rates for apo $B$ in VLDL, IDL, and LDL and triglyceride in VLDL were determined by multicompartmental analysis. This method also allowed the estimation of rates of interconversions of the lipoproteins. The two groups had similar mean ages and heights, but the obese group had a higher total body weight (131 \pm 14 vs. $66 \pm 3$ $\mathrm{kg} \pm$ SEM) and fat free mass $(81 \pm 5$ vs. $54 \pm 2 \mathrm{~kg})$ than lean controls. Plasma total lipids were similar for the two groups, and apo $B$ concentrations in VLDL, IDL, and LDL were similar in obese and lean subjects. In spite of similarity in concentrations, obese subjects compared to lean subjects had higher synthetic rates of VLDL-triglyceride (62.6 \pm 15 vs. 26.2 $\pm 7 \mathrm{~g} / \mathrm{d}, P<0.01)$, VLDL-B $(2,241 \pm 215$ vs. $1,113 \pm 72$ $\mathrm{mg} / \mathrm{d}, P<0.001)$, and LDL-B $(1,234 \pm 87$ vs. $802 \pm 83 \mathrm{mg} / \mathrm{d}$, $P<0.01$ ). Furthermore, in obese subjects, significantly higher amounts of VLDL-B were removed from the circulation without conversion to $L D L-B(1,078 \pm 159$ vs. $460 \pm 34 \mathrm{mg} / \mathrm{d}, P<0.05)$, and obese subjects had a higher fractional catabolic rate for LDL than the lean controls $\left(0.48 \pm 0.02\right.$ vs. $0.41 \pm 0.02 \mathrm{~d}^{-1}, P$ $<0.05)$. The rapid catabolism of LDL and increased metabolism of VLDL without conversion to LDL in obese individuals may be mechanisms for maintenance of LDL at normal levels despite the overproduction of its precursor.
\end{abstract}

\section{Introduction}

The obese state has long been recognized to accentuate the known risk factors for atherosclerotic disease-hyperlipidemia, hypertension, and glucose intolerance. Evidence has also been presented that obesity is an "independent" risk factor for atherosclerotic disease (1); that is, it is associated with increased risk even after adjustment for established risk factors. One possible explanation for an excess risk is that obese subjects have abnormalities in lipoprotein metabolism that do not

Dr. Egusa is with the Department of Internal Medicine, Hiroshima University School of Medicine, Hiroshima 734, Japan.

Address reprint requests to Dr. Howard, Phoenix Clinical Research Section, National Institutes of Health, 4212 N. 16 St., Phoenix, AZ 85016. 1985.

Received for publication 14 May 1984 and in revised form 26 April

The Journal of Clinical Investigation, Inc.

Volume 76, August 1985, 596-603 produce hyperlipidemia and yet accelerate atherosclerosis. For example, obese subjects without hyperlipidemia have been reported to have increases in synthesis of very low density lipoprotein (VLDL)-triglycerides (TG) ${ }^{1}(2-4)$, VLDL-apolipoprotein B (apo B) (VLDL-B) (5), low density lipoprotein (LDL)-apo B (LDL-B) (6), and total body cholesterol (7). Any or all of these abnormalities might enhance the rate of atherogenesis. Moreover, because VLDL is the precursor of LDL $(8,9)$ there could be aberrations in the interconversions of VLDL to LDL.

To further investigate possible abnormalities in lipoprotein metabolism in normolipidemic obese subjects, we have undertaken to simultaneously measure the metabolism of apo B in VLDL, IDL, and LDL of obese subjects compared to nonobese controls. The subjects were Pima Indians, a homogenous group with a high prevalence of obesity (10). This population has a virtual absence of genetic hyperlipidemia (11); thus, the effects of obesity on lipoprotein metabolism can be evaluated without interference with this potential confounding variable.

\section{Methods}

Study subjects. Two groups of young adult Pima Indian men were selected for investigation (Table I). Nine obese subjects (percentage of ideal body weight was $191 \pm 20 \%$ ) whose average age was $25 \pm 2$ yr were compared to seven nonobese subjects (age, $23 \pm 2 \mathrm{yr}$; percentage of ideal body weight, $98 \pm 4 \%$ ). All subjects had normal kidney, liver, and gastrointestinal functions as evaluated by physical examination, blood chemistry tests, and urinalysis. None had hypertension, evidence of coronary heart disease, or family history of hyperlipidemia, and none were taking any medications known to affect lipid metabolism. Subjects were not diabetic as shown by a 75-g oral glucose tolerance test; fasting and 2 -h glucose concentrations averaged $94 \pm 4$ and $111 \pm 10 \mathrm{mg} / \mathrm{dl}$ (mean \pm SEM) in the obese and $87 \pm 3$ and $105 \pm 9$ in the nonobese. Fasting and 2-h insulin concentrations were $44 \pm 8$ and $114 \pm 18 \mu \mathrm{U} / \mathrm{ml}$ in the obese and $15 \pm 2$ and $64 \pm 9$ in the nonobese groups. Before the study, written informed consent was obtained from all subjects, and the procedures in this study were approved by the Human Studies Committees of the National Institutes of Health and the Phoenix Indian Medical Center, and by the Gila River Indian Community.

Body composition was determined after an overnight fast by weighing while completely submerged in a thermoneutral water bath. The residual volume of the lung was measured simultaneously by a helium dilution technique, and fat-free mass was calculated by using the Siri formula (12).

$V L D L-B$ and $L D L-B$ metabolic study. Patients were admitted to the metabolic ward and placed on a weight maintenance diet consisting of $40 \%$ fat (polyunsaturate/saturate ratio $=0.35$ ), $45 \%$ carbohydrate, $15 \%$ protein, and $500 \mathrm{mg} / \mathrm{d}$ cholesterol. In addition patients received $150 \mathrm{mg}$ of potassium iodine daily. Coefficients of variation in weight during the study were consistently $<1 \%$. After $7 \mathrm{~d}$ on the diet and an overnight fast, $500 \mathrm{ml}$ of venous blood was collected in sterile

1. Abbreviations used in this paper: apo B or $\mathrm{E}$, apolipoprotein $\mathrm{B}$ or E; FCR, fractional catabolic rate; TG, triglycerides; VLDL-B, IDL-B, and LDL-B, very low, intermediate, and low density lipoproteinapolipoprotein B. 
Table I. Characterization of Study Subjects

\begin{tabular}{|c|c|c|c|c|c|c|c|c|c|}
\hline & Age & Height & Weight & BMI & \% IBW* & Fat-free mass & \% Fat & $\begin{array}{l}\text { Plasma } \\
\text { volume }\end{array}$ & Caloriesł \\
\hline & $y r$ & $\mathrm{~cm}$ & $k g$ & $\mathrm{~kg} / \mathrm{m}^{2}$ & & $k g$ & & $m l$ & \\
\hline \multicolumn{10}{|l|}{ Obese } \\
\hline 1 & 26 & 184 & 171 & 50 & 222 & 104 & 39 & 5,525 & 3,704 \\
\hline 2 & 31 & 171 & 131 & 45 & 196 & 84 & 36 & 4,689 & 3,069 \\
\hline 3 & 24 & 176 & 130 & 42 & 183 & 87 & 33 & 4,952 & 3,531 \\
\hline 4 & 24 & 171 & 216 & 74 & 322 & 102 & 53 & 6,033 & 4,014 \\
\hline 5 & 24 & 168 & 95 & 34 & 146 & 67 & 30 & 3,375 & 3,184 \\
\hline 6 & 18 & 173 & 123 & 41 & 178 & 76 & 38 & 3,790 & 3,184 \\
\hline 7 & 36 & 164 & 127 & 47 & 208 & 70 & 45 & 4,432 & 3,184 \\
\hline 8 & 19 & 172 & 91 & 31 & 134 & 65 & 29 & 3,423 & 3,130 \\
\hline 9 & 21 & 176 & 94 & 30 & 132 & 70 & 26 & 3,347 & 3,069 \\
\hline Mean \pm SEM & $25 \pm 2$ & $173 \pm 2$ & $131 \pm 14$ & $44 \pm 4$ & $191 \pm 20$ & $81 \pm 5$ & $36 \pm 3$ & $4,396 \pm 329$ & $3,341 \pm 111$ \\
\hline \multicolumn{10}{|l|}{ Nonobese } \\
\hline 1 & 18 & 170 & 67 & 23 & 102 & 59 & 12 & 2,847 & 2,715 \\
\hline 2 & 29 & 169 & 68 & 24 & 103 & 58 & 15 & 3,171 & 2,715 \\
\hline 3 & 22 & 172 & 67 & 23 & 99 & 54 & 20 & 2,930 & 2,702 \\
\hline 4 & 20 & 162 & 50 & 19 & 83 & 44 & 12 & 2,619 & 2,500 \\
\hline 5 & 25 & 171 & 77 & 26 & 115 & 55 & 29 & 2,932 & 2,721 \\
\hline 6 & 19 & 178 & 65 & 20 & 90 & 57 & 12 & 3,314 & 2,721 \\
\hline 7 & 25 & 171 & 65 & 22 & 97 & 49 & 24 & 3,177 & 2,721 \\
\hline Mean \pm SEM & $23 \pm 1$ & $170 \pm 2$ & $66 \pm 3$ & $23 \pm 1$ & $98 \pm 4$ & $54 \pm 2$ & $17 \pm 3$ & $2,999 \pm 90$ & $2,685 \pm 31$ \\
\hline
\end{tabular}

* Percentage of ideal body weight as determined by National Research Council Tables (32). $¥$ Calories required for weight maintenance (determined during 4 wk on metabolic ward).

plasmapheresis bags (Fenwal Laboratories, Deerfield, IL). Plasma was separated immediately by centrifugation at $600 \mathrm{~g}$ for $20 \mathrm{~min}\left(10^{\circ} \mathrm{C}\right)$ and the blood cells were reinfused. VLDLs were isolated after centrifugation for $18 \mathrm{~h}$ at $40,000 \mathrm{rpm}\left(15^{\circ} \mathrm{C}\right)$ in a Beckman preparative ultracentrifuge using a $60 \mathrm{Ti}$ rotor (Beckman Instruments, Inc., Palo Alto, CA) and concentrated and rewashed by centrifugation at 40,000 rpm for $18 \mathrm{~h}\left(15^{\circ} \mathrm{C}\right)$ using a 40 rotor. After VLDLs were isolated, the infranatant was adjusted to $d 1.025$ using a solution of $\mathrm{NaBr}$ in 0.15 $\mathrm{M} \mathrm{NaCl}, 1 \mathrm{mM}$ EDTA, $d 1.35(\mathrm{NaBr}-\mathrm{NaCl})$, and after centrifugation for $20 \mathrm{~h}$ at $40,000 \mathrm{rpm}\left(15^{\circ} \mathrm{C}\right)$ in a $60 \mathrm{Ti}$ rotor, intermediate density lipoproteins (IDLs) were removed and discarded. The infranatant was adjusted to $d 1.060$ and LDLs were isolated by centrifugation at 50,000 rpm for $20 \mathrm{~h}\left(15^{\circ} \mathrm{C}\right)$ using a $50 \mathrm{Ti}$ rotor. LDLs were rewashed and concentrated by adjusting to $d 1.070$ and centrifuging at $40,000 \mathrm{rpm}$ for $20 \mathrm{~h}\left(15^{\circ} \mathrm{C}\right)$.

The isolated VLDLs and LDLs were dialyzed against $0.15 \mathrm{M} \mathrm{NaCl}$ containing $1 \mathrm{mM}$ EDTA, pH 7.4 (EDTA-saline) for several hours. VLDLs were labeled with ${ }^{131} \mathrm{I}$ and LDLs were labeled with ${ }^{125}$ I (New England Nuclear, Boston, MA) by the iodine monochloride method of McFarlane (13). Unbound iodine was removed by extensive dialysis against EDTA-saline. The proportion of unbound iodine as determined by thin-layer chromatography (Gelman ITLC-SG sheets, Gelman Sciences, Inc., Ann Arbor, MI) in a medium of $20 \%$ trichloracetic acid containing $0.125 \%$ sodium metabisulfite averaged $0.86 \%(0.3-2.0 \%)$ for ${ }^{131}$ I-VLDL and $0.33 \%(0.0-0.6 \%)$ for ${ }^{125}$ I-LDL. Labeling efficiency averaged $9.9 \%(2.6-25.1 \%)$ for VLDL and $18.5 \%(11.4-38.2 \%)$ for LDL. The degree of lipid labeling determined by extraction with chloroform/methanol (2:1, vol/vol) (14) averaged $18.4 \%(9.8-29.1 \%)$ for ${ }^{131} \mathrm{I}-\mathrm{VLDL}$ and $4.7 \%(1.6-8.2 \%)$ for ${ }^{125} \mathrm{I}-\mathrm{LDL}$. ${ }^{131} \mathrm{I}-\mathrm{VLDL}$ and ${ }^{125} \mathrm{I}-$ LDL were diluted in the patient's own serum to obtain a final activity of $10 \mu \mathrm{Ci} / \mathrm{ml}$ and passed through a $0.22-\mu \mathrm{m}$ Millipore filter (Millipore Corp., Bedford, MA). Sterility and lack of pyrogenicity were confirmed in aliquots of the final preparation.

Approximately $5 \mathrm{~d}$ after plasmapheresis $23-29 \mu \mathrm{Ci}$ of ${ }^{131} \mathrm{I}-\mathrm{VLDL}$
(0.2-2.6 $\mathrm{mg}$ of protein) and $282 \mu \mathrm{Ci}$ of $\left[2-^{3} \mathrm{H}\right]$ glycerol (New England Nuclear, $200 \mathrm{mCi} / \mathrm{mM}$ dissolved in $0.15 \mathrm{M} \mathrm{NaCl}$ ) were injected, and $48 \mathrm{~h}$ later, 36-51 $\mu \mathrm{Ci}$ of ${ }^{125} \mathrm{I}-\mathrm{LDL}$ (0.6-3.8 $\mathrm{mg}$ of protein) were injected into an antecubital vein. From $24 \mathrm{~h}$ before and $24 \mathrm{~h}$ after the injection of ${ }^{131} \mathrm{I}-\mathrm{VLDL}$ the diet consisted of $60 \%$ of maintenance calories in a fat-free formula preparation ( $75 \%$ carbohydrate, $25 \%$ protein) which was fed every $3 \mathrm{~h}$. This was to eliminate the influx of chylomicrons during assessment of VLDL metabolism. Patients received the maintenance diet (described above) after the 24-h timepoint. Venous blood samples $(10 \mathrm{ml})$ were collected into EDTA at $-30,15,30$, and 60 min, and $2,3,4,5,9,12,18,24,30,36,42$, and $48 \mathrm{~h}$ after injection of VLDL and 15 and $30 \mathrm{~min}$, and 1, 6, 12, and $24 \mathrm{~h}$ after injection of LDL, and daily thereafter before breakfast for $14 \mathrm{~d}$. Urine specimens were collected in preservative $\left(\mathrm{NaOH}, \mathrm{KI}, \mathrm{NaHCO}_{3}\right)$ on the days of the VLDL and LDL injection in periods from 0 to 1,1 to 3, 3 to 6,6 to 12 , and 12 to $24 \mathrm{~h}$ and on all other days as $24-\mathrm{h}$ collections.

Analyses of lipoproteins during metabolic study. Lipoproteins were separated from each plasma sample as follows: $4 \mathrm{ml}$ of plasma were overlaid with EDTA-saline and centrifuged for $18 \mathrm{~h}$ at $40,000 \mathrm{rpm}$ $\left(15^{\circ} \mathrm{C}\right)$ using a 40.3 rotor. After VLDLs (the top $\sim 1 \mathrm{ml}$ ) were collected by tube slicing, the infranatant was adjusted to $d 1.019$ with $\mathrm{NaBr}$ $\mathrm{NaCl}$ and the samples were centrifuged in a type 40 rotor for $20 \mathrm{~h}$ at $40,000 \mathrm{rpm}\left(15^{\circ} \mathrm{C}\right)$. IDLs were removed by aspiration, (top $2 \mathrm{ml}$ ), and the LDLs were similarly isolated (top $3 \mathrm{ml}$ ) after the infranatant was adjusted to $d 1.063$ and centrifuged for $20 \mathrm{~h}$ at $40,000 \mathrm{rpm}$.

The specific activity of apo $B$ in each lipoprotein fraction was determined using isopropanol to isolate apo $B$ as described previously (15). Radioactivity of the apo B was measured in a Packard gamma scintillation spectrometer (Packard Instrument Co., Inc., Downers Grove, IL) which was standardized for simultaneous determination of ${ }^{131}$ I and ${ }^{125} \mathrm{I}$. Apo B precipitates were then dissolved in $1 \mathrm{~N} \mathrm{NaOH}$ for determination of protein.

Concentrations of apo B in VLDL, IDL, and LDL were measured as the difference between total protein and isopropanol-soluble protein 
as described previously (15). These concentrations were used to estimate pool sizes of apo B in each lipoprotein fraction. TG, cholesterol, and apo B measurements in each fraction were corrected for recovery computed using the total cholesterol and the sum of VLDL, IDL, LDL, and high density lipoprotein (HDL) (bottom after LDL removal) cholesterols. The same value for recovery was used for each fraction.

Radioactivity of VLDL-TG was measured using the pooled supernatants obtained after precipitation of apo B in VLDL. After the volume of the pooled supernatants was measured, phospholipids were removed by adding $5 \mathrm{~g}$ of Zeolite (Technicon Instruments Corp, Tarrytown, NY), and centrifuging at $500 \mathrm{~g}$ for $10 \mathrm{~min}$. Radioactivity was determined in a measured volume of the Zeolite supernatant, after evaporation to dryness, in a Packard liquid scintillation spectrometer equipped with an external standard for quench correction. For VLDLTG pool size, the value for VLDL-TG was corrected for recovery as described for the apo B pool sizes.

Plasma volume was determined by isotopic dilution of ${ }^{125}$ I-LDL using plasma samples obtained at 5,10 , and $20 \mathrm{~min}$ after injection of ${ }^{125}$ I-LDL. The plasma ${ }^{125}$ I-radioactivity at 0 time was computed by linear regression.

The ratio of urine to plasma radioactivity (U/P ratio) was calculated from the total radioactivity collected over a $24-\mathrm{h}$ period and the mean of plasma ${ }^{125} \mathrm{I}$-radioactivity at the beginning and end of the 24-h collection period. Urinary creatinine was monitored (16) to confirm complete collection.

Assays. Cholesterol and TG were measured in total plasma and in each lipoprotein fraction using the Autoanalyzer II (Technicon Instruments). Cholesterol was measured by the solvent extraction method of Rush et al. (17) and TG by the enzymatic method of Bucolo and Davis (18). Glucose was determined on a glucose analyzer (Beckman Instruments). Protein was measured by the Lowry method as modified by Markwell using 1\% SDS (19).
Data analysis. The specific activity data were analyzed by using a linear first-order compartmental model as described in the first preceding article (20). The same assumptions and analysis techniques were applied to the data from the present subjects and to the studies in the second preceding article (21).

Statistical analyses were performed by using the Statistical Analysis System (Cary, NC). Differences between means were evaluated using Student's unpaired $t$ test, and relationships between variables in the obese group by computing Pearson simple correlation coefficients.

\section{Results}

Plasma levels of total cholesterol were similar in obese and lean subjects (Table II). Concentrations of cholesterol, TG, and apo $B$ in VLDL were numerically but not significantly higher in the obese group; ratios of TG/apo B in VLDL were similar in the two groups. LDL-cholesterol and LDL-B were not significantly different between obese and lean subjects, but LDL-TG concentrations were higher in obese subjects. Ratios of apo B/cholesterol in LDL were similar for the two groups. The lipoprotein kinetic data for individual subjects are presented in the Appendix.

$V L D L$ metabolism. Even though VLDL-B levels were not significantly different between obese and nonobese groups, absolute synthetic rates of VLDL-B were more than twofold higher in obese subjects $(P<0.001)$ (Fig. 1). This difference persisted when synthesis was expressed per kilogram of fatfree mass. There was no difference if data were expressed per kilogram of body weight. Synthesis of VLDL-B was correlated highly with the degree of obesity as measured by percent fat (Fig. 2). Synthetic rates expressed per kilogram of fat-free mass

Table II. Plasma Lipid, Lipoprotein and Apo B Concentrations

\begin{tabular}{|c|c|c|c|c|c|c|c|c|c|c|}
\hline & \multicolumn{2}{|l|}{ Plasma } & \multicolumn{4}{|l|}{ VLDL } & \multicolumn{4}{|l|}{ LDL } \\
\hline & CHOL & TG & CHOL & TG & apo B & TG/apo B & $\mathrm{CHOL}$ & TG & apo B & apo B/CHOL \\
\hline & \multicolumn{2}{|c|}{$m g / d l$} & \multicolumn{4}{|c|}{$m g / d l$} & \multicolumn{2}{|c|}{$m g / d l$} & & \\
\hline \multicolumn{11}{|l|}{ Obese } \\
\hline 1 & $129 \pm 2$ & $100 \pm 2$ & $11 \pm 0$ & $61 \pm 1$ & 8.8 & 6.9 & $62 \pm 1$ & $13 \pm 1$ & 51.3 & 0.83 \\
\hline 2 & $195 \pm 2$ & $158 \pm 3$ & $17 \pm 1$ & $104+4$ & 8.5 & 12.2 & $96 \pm 2$ & $29 \pm 1$ & 67.6 & 0.70 \\
\hline 3 & $147 \pm 2$ & $126 \pm 4$ & $12 \pm 0$ & $97 \pm 3$ & 9.0 & 10.8 & $84 \pm 1$ & $19 \pm 0$ & 59.6 & 0.71 \\
\hline 4 & $131 \pm 3$ & $182 \pm 7$ & $21 \pm 1$ & $142 \pm 5$ & 14.0 & 10.1 & $59 \pm 1$ & $19 \pm 0$ & 50.7 & 0.86 \\
\hline 5 & $192 \pm 3$ & $239 \pm 5$ & $34 \pm 1$ & $189 \pm 5$ & 11.4 & 16.6 & $105 \pm 1$ & $28 \pm 2$ & 74.7 & 0.71 \\
\hline 6 & $174 \pm 2$ & $113 \pm 4$ & $11 \pm 1$ & $73 \pm 4$ & 98.8 & 7.4 & $101 \pm 1$ & $24 \pm 0$ & 64.6 & 0.64 \\
\hline 7 & $114 \pm 4$ & $96 \pm 4$ & $6 \pm 0$ & $45 \pm 2$ & 5.5 & 8.2 & $51 \pm 1$ & $21 \pm 1$ & 49.6 & 0.97 \\
\hline 8 & $129 \pm 1$ & $115 \pm 2$ & $11 \pm 0$ & $82 \pm 2$ & 5.9 & 13.9 & $63 \pm 1$ & $25 \pm 1$ & 47.4 & 0.75 \\
\hline 9 & $162 \pm 3$ & $292 \pm 7$ & $42 \pm 2$ & $229 \pm 9$ & 17.6 & 13.0 & $73 \pm 1$ & $35 \pm 1$ & 77.1 & 1.05 \\
\hline Mean $\pm S E$ & $153 \pm 10$ & $160 \pm 24$ & $19 \pm 4$ & $114 \pm 21$ & $10.1 \pm 1.3$ & $11.0 \pm 1.1$ & $77 \pm 7$ & $24 \pm 2$ & $60.3 \pm 3.8$ & $0.80 \pm 0.05$ \\
\hline \multicolumn{11}{|l|}{ Nonobese } \\
\hline 1 & $105 \pm 3$ & $106 \pm 5$ & $11 \pm 0$ & $73 \pm 4$ & 5.7 & 12.8 & $54 \pm 1$ & $17 \pm 0$ & 41.7 & 0.71 \\
\hline 2 & $135 \pm 3$ & $236 \pm 12$ & $26 \pm 2$ & $183 \pm 9$ & 12.0 & 15.2 & $62 \pm 2$ & $19 \pm 1$ & 56.7 & 0.91 \\
\hline 3 & $163 \pm 3$ & $77 \pm 2$ & $8 \pm 0$ & $46 \pm 2$ & 7.0 & 6.6 & $90 \pm 1$ & $11 \pm 0$ & 87.7 & 0.97 \\
\hline 4 & $162 \pm 1$ & $104 \pm 2$ & $16 \pm 1$ & $75 \pm 3$ & 11.3 & 6.6 & $84 \pm 1$ & $12 \pm 0$ & 73.6 & 0.88 \\
\hline 5 & $183 \pm 2$ & $163 \pm 8$ & $20 \pm 1$ & $112 \pm 4$ & 9.7 & 11.5 & $100 \pm 2$ & $17 \pm 0$ & 85.9 & 0.86 \\
\hline 6 & $117 \pm 3$ & $65 \pm 3$ & $7 \pm 0$ & $35 \pm 1$ & 3.5 & 10.0 & $53 \pm 0$ & $15 \pm 2$ & 43.3 & 0.82 \\
\hline 7 & $142 \pm 6$ & $80 \pm 2$ & $11 \pm 1$ & $46 \pm 2$ & 5.8 & 7.9 & $63 \pm 2$ & $17 \pm 1$ & 51.7 & 0.82 \\
\hline Mean \pm SE & $146 \pm 10$ & $119 \pm 23$ & $14 \pm 2$ & $81 \pm 19$ & $7.9 \pm 1.2$ & $10.1 \pm 1.2$ & $72 \pm 7$ & $15 \pm 1$ & $62.9 \pm 7.3$ & $0.86 \pm 0.02$ \\
\hline Differences & NS & NS & NS & NS & NS & NS & NS & $P<0.1$ & NS & NS \\
\hline
\end{tabular}

Values are the mean \pm SEM for all time points during the metabolic study. VLDL were collected at $d<1.006$ and LDL at $d 1.019-1.063$.

Values for VLDL and LDL-TG, cholesterol (CHOL), and apo B were corrected for recovery as described in Methods. 


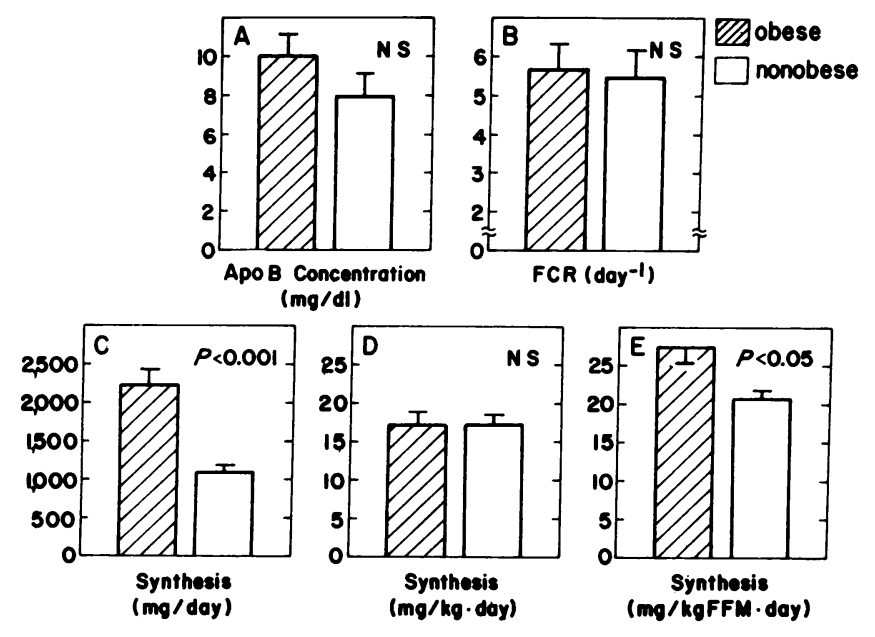

Figure 1. Metabolism of VLDL-B in obese and nonobese groups. Bars represent mean \pm SEM. Numbers in upper right corners are $P$ values comparing the two groups.

were significantly correlated with degree of obesity $(r=0.49$, $P<0.05$, data not shown). VLDL-B transport was also highly correlated with caloric consumption $(r=0.81, P<0.001)$.

Data on VLDL-TG metabolism were available for five of the nine obese and six of the seven nonobese subjects (Table III). VLDL-TG production expressed as milligram/day was approximately twofold higher in the obese group $(P<0.05)$. Production of VLDL-TG also was higher when expressed per kilogram of fat-free mass but the difference did not reach significance $(P<0.10)$. There was no difference when expressed per kilogram of total body weight. In the obese subjects there also was a significantly lower fraction of VLDL-TG synthesis occurring via the slow pathway. Ratios of VLDL-TG/VLDL$B$ production were similar in the two groups.

IDL metabolism. Plasma concentrations of IDL-B were similar for the two groups (Fig. 3). The mean fractional catabolic rate (FCR) of IDL-B was numerically but not significantly higher in the obese group, but absolute transport rates of IDL-B were significantly increased in obese subjects. Normalization of transport rates to fat-free mass or kilograms of body weight, however, obliterated the differences between the two groups.

LDL metabolism. LDL-B concentrations were similar in obese and lean subjects (Fig. 4). Despite this similarity in concentrations, absolute synthetic rates were twice as high in obese subjects. This difference in transport rates was negated when data were normalized for fat-free mass or kilograms of total body weight. When the data of obese and lean subjects were combined, there was a significant correlation between absolute synthesis of LDL-B and the percentage of total body

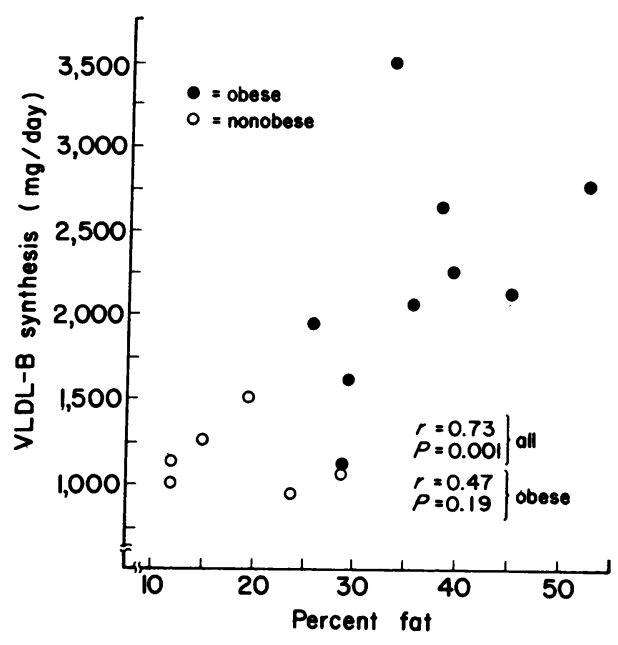

Figure 2. Relationship between VLDL-B synthesis and obesity as measured by percent fat. Correlation coefficients are presented for all subjects and also for those in the obese group.

weight as fat (Fig. $5 \mathrm{~A}$ ), but there was no correlation between LDL synthesis and obesity, calorie intake, or plasma volume when transport was normalized to fat-free mass (data not shown).

The FCR of LDL-B was significantly higher in the obese group, (Fig. 4); The FCR was correlated significantly with the percentage of body fat (Fig. $5 \mathrm{~B}$ ) and to the mass of the plasma pool of LDL-B ( $r 0.70, P 0.003$, data not shown).

Integrated metabolism of apo $B$. The rates of transformation of VLDL-B to LDL-B are compared for the two groups in Fig. 6. The mass of apo B passing through the VLDL chain and to LDL averaged $1,164 \pm 99 \mathrm{mg} / \mathrm{d}$ for the obese group and $672 \pm 65 \mathrm{mg} / \mathrm{d}$ for the nonobese; this difference was highly significant $(P<0.001)$. In both groups, the total mass of apo $B$ entering LDL passed through IDL. The differences in conversion rates between the two groups were eliminated when data were normalized to fat-free mass or kilograms of total body weight. The actual amount of apo $B$ passing through the VLDL-B chain and not reaching LDL-B was much higher in the obese group than in the lean; this difference also was significant when transport rates were expressed per kilogram of fat-free mass, but not per kilogram of body weight. The absolute amount of VLDL-B transported through the delipidation chain and not converted to LDL was significantly correlated with the percentage of body fat (Fig. 7) and, this correlation between the non-LDL pathway and the percentage of fat was significant when transport was normalized to fatfree mass $(r=0.49, P<0.05)$.

The quantity of apo B entering LDL independent of the VLDL delipidation chain was relatively low in both groups;

Table III. Comparison of VLDL-TG Metabolism in Obese and Nonobese Subjects

\begin{tabular}{|c|c|c|c|c|c|c|}
\hline & $\begin{array}{l}\text { VLDL-TG } \\
\text { synthesis }\end{array}$ & $\begin{array}{l}\text { VLDL-TG } \\
\text { synthesis }\end{array}$ & $\begin{array}{l}\text { VLDL-TG } \\
\text { synthesis }\end{array}$ & FCR & Slow pathway & $\begin{array}{l}\text { TG synthesis } \\
\text { B synthesis }\end{array}$ \\
\hline & $m g / d$ & $\mathrm{mg} / \mathrm{kg} F F M / d$ & $\mathrm{mg} / \mathrm{kg} / \mathrm{d}$ & $d^{-1}$ & $\%$ & \\
\hline Obese $(n=5)$ & $48,672 \pm 9,734^{*}$ & $618 \pm 110$ & $367 \pm 15$ & $12.2 \pm 2.3$ & $44 \pm 9^{*}$ & $24 \pm 3$ \\
\hline Nonobese $(n=6)$ & $26,200 \pm 7,300$ & $480 \pm 121$ & $407 \pm 104$ & $11.4 \pm 1.5$ & $62 \pm 5$ & $22 \pm 5$ \\
\hline
\end{tabular}

Values are mean \pm SEM. Data are available for obese subjects $3,4,6-8$, and for all nonobese subjects except no. 5 . $^{*} P<0.05$. 

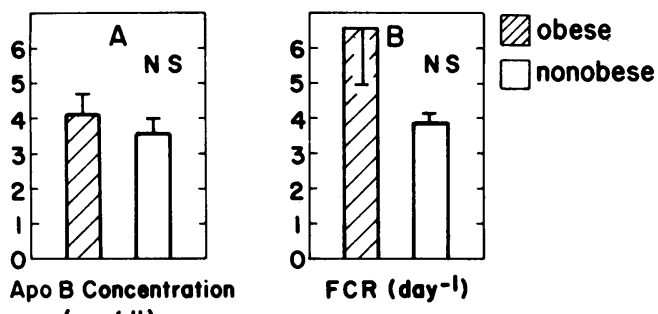
$(\mathrm{mg} / \mathrm{dl})$
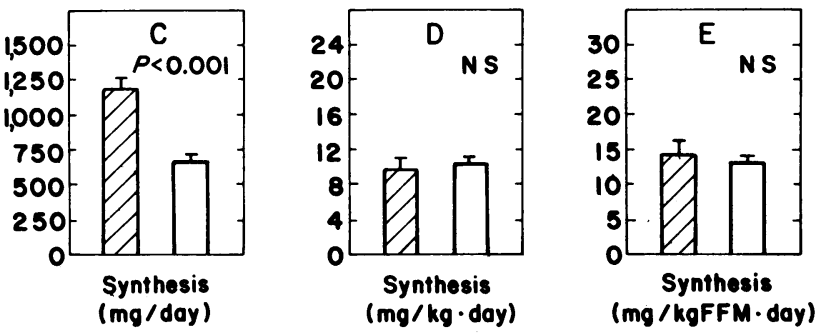

Figure 3. Metabolism of IDL-B in obese in nonobese groups. Format is similar to that of Fig. 1.

the percentage of LDL-B derived from "direct synthesis" was greater in the nonobese group (16\%) than in the obese group (7\%), although in each group there was a range varying from $0 \%$ to as much as $25 \%$.

Total transport of apo B was estimated to be $2,379 \pm 221$ $\mathrm{mg} / \mathrm{d}$ in the obese group and $1,506 \pm 129 \mathrm{mg} / \mathrm{d}$ in the lean, a difference that was statistically significant $(P<0.01)$.

\section{Discussion}

The present study was conducted to examine several aspects of the metabolism of apo B and TG in lipoproteins of obese patients. It should be noted at the outset that comparison of kinetic data between obese and lean subjects presents difficulties. Expressing data per kilogram of total body mass is the least valuable for comparisons of metabolic processes, because the increase in total body weight in obesity reflects mainly increases in fat mass, which may have different contributions to lipoprotein metabolism than does fat-free mass. Normalization to kilograms of ideal body weight $(3,4,6)$ merely corrects wholebody rates for variations in height among different individuals. Furthermore, to normalize both obese and nonobese subjects
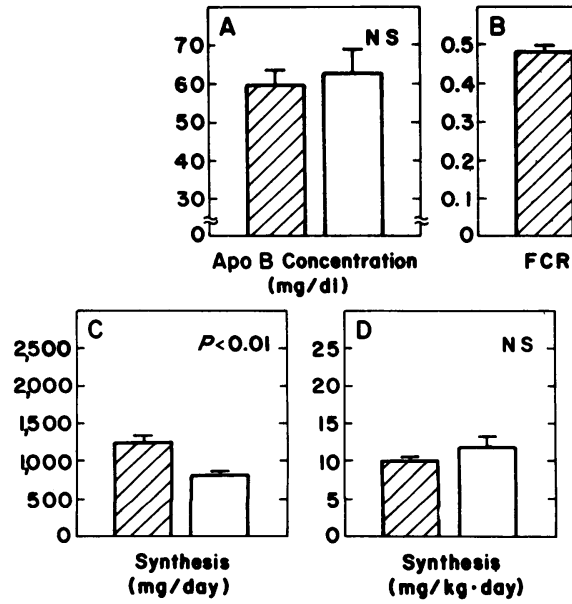
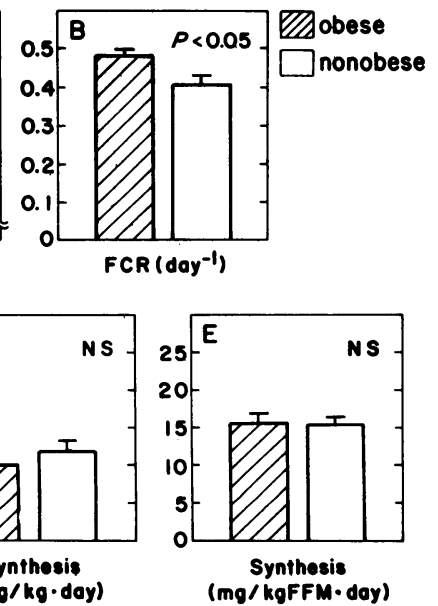

Figure 4. Metabolism of LDL-B in obese vs. nonobese groups. Format is similar to that of Fig. 1. to total weight or ideal weight fails to disclose any of the internal causes for changes in the lipoprotein transport. In the attempt to circumvent this drawback, we measured fat-free mass using underwater weighing. Normalization to fat-free mass enabled us to make some assessment of the relative contributions of the masses of adipose tissue and fat-free tissues to transport rates of VLDL and LDL.

The quantity of adipose tissue and fat-free mass are not the only factors that may affect kinetics of lipoproteins in obese patients. For example, relatively high intakes of total calories in the obese state may overly stimulate the synthesis of lipoproteins. Furthermore, the present study showed that obese patients have yet another difference, namely, a marked increase in plasma volume; this increase could cause a lowering of lipoprotein concentrations by diluting them into a larger volume. Therefore, any consideration of differences between lean and obese patients must take into account not only differences in weight, but other changes that accompany the obese state.

$V L D L$ transport. The obese patients in this study did not have abnormally high concentrations of VLDL-TG or VLDLB. However, there were other distinct abnormalities in metabolism of these moieties. Both absolute production rates and rates per kilogram of fat-free mass of VLDL-TG and VLDLB were increased markedly in our obese subjects, as has been reported previously in other obese patients (2-5). Normal VLDL-TG and VLDL-B levels appeared to be maintained because, as mentioned above, they had greatly increased plasma volumes that diluted the pool of lipoproteins; FCR was also marginally increased.

Several mechanisms could be responsible for the increased production of VLDL-TG in obesity. Excess release of free fatty acids from adipose tissue (22) and elevated plasma insulin (2) have been previously implicated. In addition to these endogenous factors, the effects of the higher caloric intake required to maintain the obese state must be considered (23), because there was a significant relationship between calorie intake and VLDL-TG production. The current study showed a high correlation between the percentage of body weight as fat and synthesis of VLDL-B (Fig. 2); in that VLDL-B synthesis was elevated significantly even when expressed per fat-free mass, this suggests that a high flux of free fatty acids could be one cause of apo B overproduction. It therefore seems likely that an increase influx of nutrients may initiate the overproduction of VLDL, whereas high outputs may be maintained by an increase in metabolites flowing from excess adipose tissue and possibly also from a greater fat-free mass.

The question has not been resolved previously whether the overproduction of VLDL-TG in obese subjects is associated with an increase in the number of VLDL particles secreted, or whether the output of particles is unchanged but each particle is merely expanded with TG. The current study clearly demonstrated that the increased secretion of VLDL-TG in our obese subjects was accompanied by a high output of VLDL$B$, and the TG/apo B ratio in obese subjects was similar for obese and nonobese patients. Assuming that the apo B content per particle does not change, maintenance of the obese state appears to increase the number of VLDL particles entering the plasma. This high influx of lipoproteins might contribute to the increased risk for coronary heart disease observed in obese patients.

IDL transport. In the present study, IDL concentrations were similar in both groups. Again, however, absolute transport 

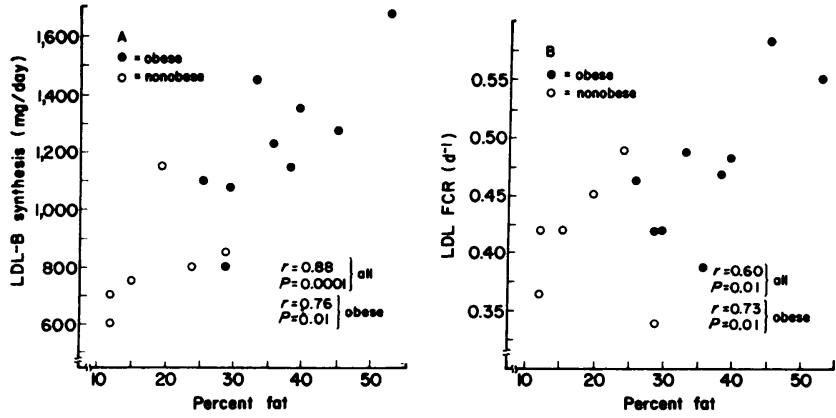

Figure 5. (A) Relationship between LDL-B synthesis and percent fat. (B) Relationship between LDL catabolism (FCR) and percent fat.

rates of IDL-B were higher in the obese group. In both obese and lean subjects, the FCRs of IDL-B were relatively high, similar to those of VLDL-B. IDL in these subjects thus behaved as though it was the terminal compartment of the VLDL chain, and this suggests that lipolysis of the remaining TG was the crucial factor determining the turnover rate of IDL.

$L D L$ transport. Concentrations of LDL-cholesterol and LDL-B were not increased in the obese Pima subjects. Nevertheless, absolute transport rates of LDL-B were elevated in these patients. This finding is in accord with a report of Kesäniemi and Grundy (6) who observed that Caucasians with marked obesity have increased transport of LDL-B despite normal LDL cholesterol. On the basis of the present study, the high production of LDL in obese patients most likely is the consequence of a high synthesis of VLDL-B, as will be considered again below. Concentrations of LDL cholesterol were maintained in the normal range in our obese subjects by the high FCR of LDL-B. Several factors could have contributed to the high FCR. If LDL is removed at multiple sites throughout the body, a large capacity for LDL clearance in obese subjects might in part be the consequence of an increase in lean-body mass. Furthermore, adipose tissue apparently has the ability to bind and internalize LDL (24), and an excessively large adipose mass might dispose of significant quantities of LDL. It has been reported that insulin can enhance the catabolism of $\operatorname{LDL}(25,26)$, and the hyperinsulinemia of obesity could accelerate clearance of LDL. A high FCR in obese subjects also could be related to an abnormal composition of LDL.
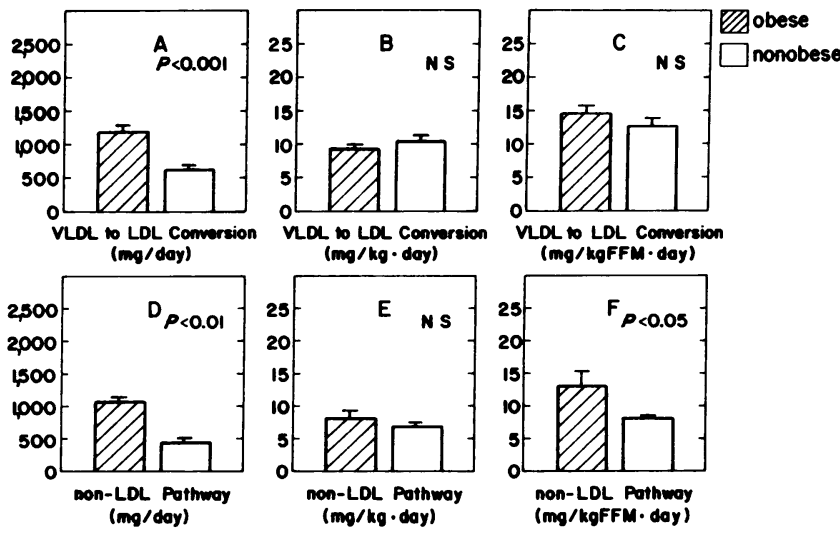

Figure 6. Interconversion of VLDL-B and LDL-B in obese and nonobese groups. Format is similar to that in Fig. 1.

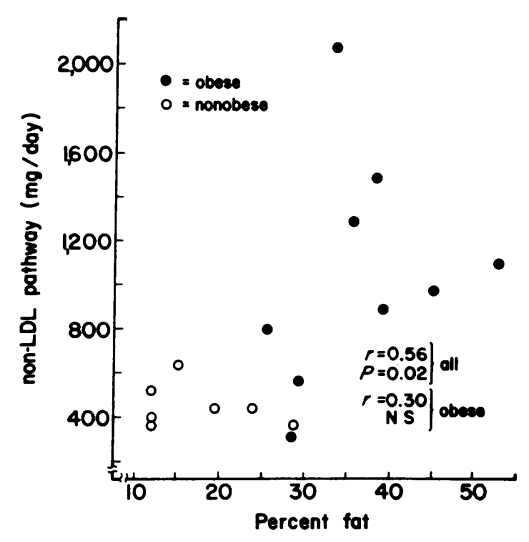

Figure 7. Relationship between non-LDL pathway and obesity as measured by percent fat.

The obese group had an increase in LDL-TG; this could reflect an incomplete delipidation of IDL; and if so, LDL may retain small amounts of apo $E$ that could facilitate its clearance via $\mathrm{B} / \mathrm{E}$ receptors (27).

Conversion of VLDL to $L D L$. Despite the transfer of an abnormally high mass of apo B from VLDL to LDL in the obese subjects of this study, the amount of VLDL-B removed directly from the circulation also was elevated significantly. This high portion of direct removal of VLDL-B could be a significant factor preventing development of hypercholesterolemia in obese subjects. An enhanced direct removal of VLDLB might have several causes, such as those suggested for the increased FCR of LDL-B. The data suggest that it is influenced in some way by the fat mass, because this pathway was increased even when data were expressed per fat-free mass. Whether all of VLDL remnants are removed by the liver is unclear. Previous studies raise the possibility that extrahepatic tissues also could remove a portion. For instance, Bierman et al. (28) reported that VLDL remnants can be taken up by aortic smooth muscle cells, and receptor-mediated catabolism of VLDL has been claimed in fibroblasts and macrophages $(29,30)$. Adipocytes, which incorporate free fatty acids released from VLDL via lipoprotein lipase, also might take up some remnants. These possible pathways however would require that VLDL remnants leave the vascular space, a process yet to be demonstrated.

Integrated metabolism of apo B in lean and obese subjects. The transport data for apo B in lean and obese Pima subjects

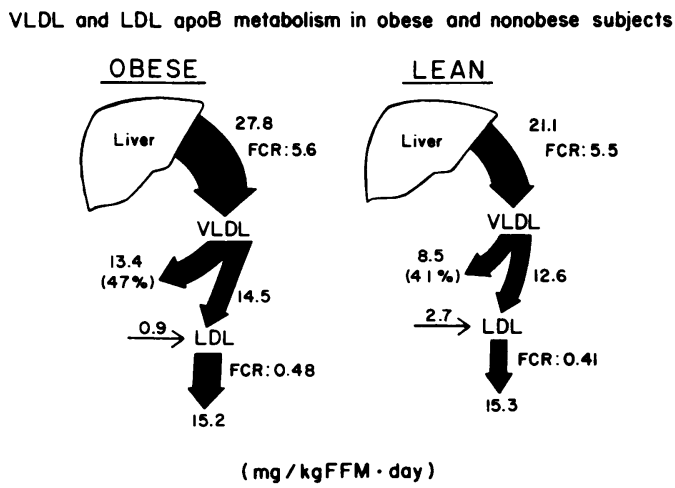

Figure 8. Comparison of apo B metabolism in lean and obese subjects. In lean subjects estimated total apo B production (21) in $\mathrm{mg} / \mathrm{kg} \cdot \mathrm{d}$, was $23.1 \pm 1.7$. 
are summarized in Fig. 8. Total input of VLDL-B in lean subjects in the study averaged $23.1 \mathrm{mg} / \mathrm{kg} \cdot$ day. This value is similar to that found in older, nonobese Caucasian men (21). In obese subjects, the influx of both VLDL-B and VLDL-TG was increased. Direct removal of VLDL remnants also was increased in the obese. This diverted a considerable portion of the excess VLDL-B, but even so, absolute production of LDL$B$ was increased in obese subjects. LDL-B levels were near the normal range because of a higher FCR of LDL. Thus despite overproduction of VLDL-B in this population of obese subjects, hypercholesterolemia was prevented by two mechanisms that both may be mediated by B-100/E receptors-enhanced direct removal of VLDL remnants and increase in the fractional clearance of LDL. Despite these adjustments, the total flux of LDL particles was increased in obese subjects, a process that might have atherogenic potential. Another factor that theoretically could enhance atherogenicity of LDL in obese subjects is an abnormal composition of LDL. A previous report (6). claimed that the ratio of apo B to cholesterol in LDL is increased in Caucasian obese subjects, and in this study we observed an increased TG content of LDL. These abnormalities could render LDL more readily taken up by cells of the arterial wall. Finally, the current study suggests a way in which obesity could raise concentrations of $\mathrm{LDL}$ in some people. In those who have a defect in receptor-mediated clearance of VLDL remnants and LDL for other reasons, as in familial hypercholesterolemia (31), obesity should worsen hypercholesterolemia by increasing influx of LDL.

\section{Acknowledgments}

The authors wish to acknowledge the excellent technical assistance of Annette Kennedy and John Brown, the secretarial assistance of Verna
Kuwanhoyioma and Gloria Williams, and the nursing and dietary staffs of the Phoenix Clinical Research Unit for their support.

\section{References}

1. Kannel, W. B., T. Gorden, and W. P. Castelli. 1979. Obesity, lipids, and glucose intolerance. The Framingham study. Am. J. Clin. Nutr. 32:1238-1245.

2. Olefsky, J., G. M. Reaven, and J. W. Farquhar. 1974. Effects of weight reduction and obesity on lipid and carbohydrate metabolism in normal and hyperlipoproteinemic subjects. J. Clin. Invest. 53:6476.

3. Reaven, G. M., and R. M. Berstein. 1978. Effect of obesity on the relationship between very low density lipoprotein production rate and plasma triglyceride concentration in normal and hypertriglyceridemic subjects. Metab. Clin. Exp. 27:1047-1054.

4. Grundy, S. M., H. Y. Mok, L. Zech, D. Steinberg, and M. Berman. 1979. Transport of very low density lipoprotein triglycerides in varying degrees of obesity and hypertriglyceridemia. J. Clin. Invest. 63:1274-1283.

5. Kissebah, A. H., S. Alfarsi, and P. W. Adams. 1981. Integrated regulation of very low density lipoprotein triglyceride and apolipoproteinB kinetics in man: Normolipemic subjects, familial hypertriglyceridemia and familial combined hyperlipidemia. Metab. Clin. Exp. 30:856-868.

6. Kesäniemi, Y. A., and S. M. Grundy. 1983. Increased low density lipoprotein production associated with obesity. Arteriosclerosis. 3:170-177.

7. Miettinen, T. A. 1971. Cholesterol production in obesity. Circulation. 44:842-850.

8. Bilheimer, D. W., S. Eisenberg, and R. I. Levy. 1972. The metabolism of very low density lipoprotein proteins. I. Preliminary in vitro and in vivo observations. Biochim. Biophys. Acta. 260:212-221.

9. Sigurdsson, G., A. Nicoll, and B. Lewis. 1975. Conversion of very low density lipoprotein to low density lipoprotein. J. Clin. Invest. 56:1481-1490.

10. Knowler, W. C., D. J. Pettitt, P. J. Savage, and P. H. Bennett.

\section{Appendix}

\begin{tabular}{|c|c|c|c|c|c|c|c|c|c|c|c|c|c|c|c|}
\hline \multicolumn{7}{|l|}{ VLDL } & \multicolumn{6}{|l|}{ IDL } & \multicolumn{3}{|l|}{ LDL } \\
\hline & \multirow{2}{*}{$\begin{array}{l}\begin{array}{l}\text { Apo B } \\
\text { pool }\end{array} \\
m g\end{array}$} & \multirow{2}{*}{$\frac{\text { FCR }}{d^{-1}}$} & \multirow{2}{*}{$\begin{array}{l}\begin{array}{l}\text { Residence } \\
\text { time }\end{array} \\
d\end{array}$} & \multicolumn{3}{|l|}{ Turnover } & $\begin{array}{l}\text { Apo B } \\
\text { pool }\end{array}$ & FCR. & $\begin{array}{l}\text { Residence } \\
\text { time }\end{array}$ & \multicolumn{3}{|l|}{ Turnover } & $\begin{array}{l}\text { Apo B } \\
\text { pool }\end{array}$ & FCR & $\begin{array}{l}\text { Residence } \\
\text { time }\end{array}$ \\
\hline & & & & $m g / d$ & $m g / k g-d$ & $\begin{array}{l}m g / \\
F F M-d\end{array}$ & $m g$ & $d^{-1}$ & $d$ & $m g / d$ & $m g / k g-d$ & $\begin{array}{l}m g / \\
F F M-d\end{array}$ & $m g$ & $d^{-1}$ & $d$ \\
\hline \multicolumn{16}{|l|}{ Obese } \\
\hline 1 & 486 & 4.7 & 0.21 & 2,268 & 13.1 & 21.8 & 218 & 5.3 & 0.19 & 1,374 & 8.0 & 13.2 & 2,834 & 0.48 & 2.1 \\
\hline 2 & 399 & 5.1 & 0.19 & 2,047 & 15.6 & 24.4 & 264 & 2.5 & 0.39 & 776 & 5.9 & 9.2 & 3,170 & 0.39 & 2.6 \\
\hline 3 & 446 & 7.8 & 0.13 & 3,493 & 26.9 & 40.2 & 141 & 15.8 & 0.06 & 1,423 & 10.9 & 16.3 & 2,951 & 0.49 & 2.0 \\
\hline 4 & 845 & 3.3 & 0.31 & 2,764 & 12.8 & 27.1 & 154 & 9.8 & 0.14 & 1,693 & 7.8 & 16.6 & 3,059 & 0.55 & 1.8 \\
\hline 5 & 385 & 4.1 & 0.24 & 1,595 & 16.7 & 23.8 & 190 & 4.1 & 0.24 & 1,036 & 10.9 & 15.5 & 2,521 & 0.42 & 2.4 \\
\hline 6 & 371 & 7.1 & 0.14 & 2,621 & 21.3 & 34.5 & 190 & 5.8 & 0.17 & 1,151 & 9.4 & 15.1 & 2,448 & 0.47 & 2.1 \\
\hline 7 & 244 & 8.8 & 0.11 & 2,114 & 16.6 & 30.3 & 250 & 3.2 & 0.32 & 1,165 & 9.2 & 16.7 & 2,198 & 9.58 & 1.7 \\
\hline 8 & 202 & 6.7 & 0.15 & 1,360 & 14.9 & 20.9 & 62 & 9.9 & 0.10 & 814 & 8.9 & 12.5 & 1,623 & 0.50 & 2.0 \\
\hline 9 & 589 & 3.2 & 0.31 & 1,908 & 20.3 & 27.2 & 197 & 2.6 & 0.38 & 1,022 & 10.9 & 14.6 & 2,580 & 0.48 & 2.6 \\
\hline Mean \pm SE & $441 \pm 64$ & $5.6 \pm 0.7$ & $0.20 \pm 0.02$ & $2,241 \pm 215$ & $17.6 \pm 1.5$ & $27.8 \pm 2.1$ & $187 \pm 20$ & $6.6 \pm 1.5$ & $0.22 \pm 0.4$ & $1,162 \pm 99$ & $9.1 \pm 1.6$ & $14.4 \pm 1.8$ & $2,598 \pm 161$ & $0.48 \pm 0.02$ & $2.1 \pm 0.1$ \\
\hline \multicolumn{16}{|l|}{ Nonobese } \\
\hline 1 & 162 & 7.1 & 0.14 & 1,156 & 17.3 & 19.6 & 85 & 4.2 & 0.24 & 646 & 9.6 & 10.9 & 1,187 & - & - \\
\hline 2 & 380 & 3.4 & 0.30 & 1,279 & 18.8 & 22.1 & 98 & 2.8 & 0.36 & 649 & 9.5 & 11.2 & 1,798 & 0.42 & 2.4 \\
\hline 3 & 205 & 7.2 & 0.14 & 1,481 & 22.1 & 27.5 & 100 & 4.4 & 0.23 & 1,036 & 15.5 & 19.2 & 2,597 & 0.45 & 2.2 \\
\hline 4 & 296 & 3.3 & 0.30 & 982 & 19.6 & 22.3 & 92 & 3.5 & 0.28 & 606 & 12.1 & 13.8 & 1,928 & 0.36 & 2.8 \\
\hline 5 & 294 & 3.7 & 0.27 & 1,059 & 13.8 & 19.3 & 172 & 2.9 & 0.35 & 697 & 9.1 & 12.7 & 2,519 & 0.34 & 2.8 \\
\hline 6 & 116 & 8.7 & 0.11 & 1,013 & 15.6 & 17.6 & 88 & 5.2 & 0.19 & 533 & 8.2 & 9.3 & 1,435 & 0.38 & 2.6 \\
\hline 7 & 184 & 5.2 & 0.19 & 960 & 14.8 & 19.4 & 149 & 3.4 & 0.29 & 577 & 8.1 & 10.7 & 1,642 & 0.49 & 2.0 \\
\hline Mean \pm SE & $\begin{array}{l}234 \pm 35 \\
P<0.01\end{array}$ & $\begin{array}{l}5.5 \pm 0.8 \\
\text { NS }\end{array}$ & $\begin{array}{l}0.21 \pm 0.03 \\
\text { NS }\end{array}$ & $\begin{array}{l}1,133 \pm 72 \\
P<0.001\end{array}$ & $\begin{array}{l}17.4 \pm 1.1 \\
\text { NS }\end{array}$ & $\begin{array}{l}21.1 \pm 1.2 \\
P<0.05\end{array}$ & $\begin{array}{l}112 \pm 13 \\
P<0.01\end{array}$ & $\begin{array}{r}3.8 \pm 0.3 \\
P<0.10\end{array}$ & $\begin{array}{l}0.28 \pm 0.02 \\
\text { NS }\end{array}$ & $\begin{array}{r}671 \pm 65 \\
P<0.001\end{array}$ & $\begin{array}{l}10.3 \pm 1.0 \\
\text { NS }\end{array}$ & $\begin{array}{l}12.5 \pm 1.2 \\
\text { NS }\end{array}$ & $\begin{array}{l}1,868 \pm 197 \\
P<0.01\end{array}$ & $\begin{array}{l}0.41 \pm 0.02 \\
P<0.05\end{array}$ & $\begin{array}{l}2.5 \pm 0.1 \\
\text { NS }\end{array}$ \\
\hline
\end{tabular}

Rate constants for all subjects are available on request. FFM, fat-free mass. * Total apo B production was computed as the sum of VLDL-B transport plus "direct" input of LDL increment by the \% of direct removal from this pathway according to the hypothesis presented in Fis. 10, reference 20. 
1981. Diabetes incidence in the Pima Indians. Contributions of obesity and parental diabetes. Am. J. Epidemiol. 113:144-156.

11. Howard, B. V., M. P. Davis, D. J. Pettitt, W. C. Knowler, and P. H. Bennett. 1983. Plasma and lipoprotein cholesterol and triglyceride concentrations in the Pima Indians: distributions differing from those of Caucasians. Circulation. 68:714-24.

12. Brozek, J., and A. Henschel. 1961. Techniques for measuring body composition. Natural Academy of Sciences-National Research Council, Washington, DC.

13. McFarlane, A. S. 1958. Efficient trace-labelling of proteins with iodine. Nature (Lond.). 182:53.

14. Folch, J., M. Lees, and G. H. Sloane-Stanley. 1957. A simple method for the isolation and purification of total lipids from animal tissues. J. Biol. Chem. 226:497-509.

15. Egusa, G., D. W. Brady, S. M. Grundy, and B. V. Howard. 1983. Isopropanol precipitation method for the determination of apolipoprotein B specific activity and plasma concentrations during metabolic studies of very low density lipoprotein and low density lipoprotein apolipoprotein B. J. Lipid Res. 24:1261-1267.

16. Autoanalyzer Methodology. Method \#N-11B. Technicon Instruments, Tarrytown, New York.

17. Rush, R. L., L. Leon, and J. Turrell. 1970. Automated simultaneous cholesterol and triglyceride determination on the Auto Analyzer Instrument. In Advances in Automated Analyses. Thurman, Miami, FL. 503-511.

18. Bucolo, G., and H. Davis. 1973. Quantitative determination of serum triglycerides by use of enzymes. Clin. Chem. 39:475-482.

19. Markwell, M. A. K., S. M. Haas, L. L. Bieber, and N. E. Toebert. 1978. A modification of the Lowry procedure to simplify protein determination in membrane and lipoprotein samples. Anal. Biochem. 87:206-210.

20. Beltz, W. F., Y. A. Kesäniemi, B. V. Howard, and S. M. Grundy. 1985. Development of an intergrated model for analyses of the kinetics of apolipoprotein B in plasma very low density lipoproteins, intermediate density lipoproteins, and low density lipoproteins. J. Clin. Invest. 76:575-585.

21. Kesäniemi, Y. A., W. F. Beltz, and S. M. Grundy. 1985.
Comparisons of metabolism of apolipoprotein B in normal subjects, obese patients, and patients with coronary heart disease. J. Clin. Invest. 76:586-595.

22. Nestel, P. J., and H. M. Whyte. 1968. Plasma free fatty acid and triglyceride turnover in obesity. Metab. Clin. Exp. 17:1122-1128.

23. Barter, P. J., and P. J. Nestel. 1972. Plasma free fatty acid transport during prolonged glucose consumption and its relationship to plasma triglyceride fatty acids in man. J. Lipid Res. 13:483-490.

24. Angel, A., M. A. D'Dosta, and R. Yuen. 1979. Low density lipoprotein binding, internalization, and degradation in human adipose cells. Can. J. Biochem. 57:578-587.

25. Chait, A., E. L. Bierman, and J. J. Albers. 1978. Regulatory role of insulin in the degradation of low density lipoprotein by cultured human skin fibroblasts. Biochim. Biophys. Acta. 529:292-299.

26. Mazzone, T., D. Foster, and A. Chait. 1982. Insulin stimulates the catabolism of low density lipoprotein in man. Clin. Res. 30:440a. (Abstr.)

27. Mahley, R. W., D. Hui, T. L. Innerarity, and K. H. Wesigraber. 1981. Two independent lipoprotein receptors on hepatic membranes of dog, swine and man. Apo B-E and apo E receptors. J. Clin. Invest. 68:1197-1206.

28. Bierman, E. L., S. Eisenberg, O. Stein, and Y. Stein. 1973. Very low density lipoprotein "remnant" particles: uptake by aortic smooth muscle cells in culture. Biochim. Biophys. Acta. 329:163-169.

29. Gianturco, S. H., F. B. Brown, A. M. Gotto, Jr., and W. A. Bradley. 1982. Receptor-mediated uptake of hypertriglyceridemic very low density lipoproteins by normal human fibroblasts. J. Lipid Res. 23:984-993.

30. Gianturco, S. H., W. A. Bradley, A. M. Gotto, Jr., J. D. Morrisett, and D. L. Peavy. 1982. Hypertriglyceridemic very low density lipoproteins induce triglyceride synthesis and accumulation in mouse peritoneal macrophages. J. Clin. Invest. 70:168-178.

31. Goldstein, J. L., T. Kita, and M. S. Brown. 1983. Defective lipoprotein receptors and arteriosclerosis. N. Engl. J. Med. 309:288296.

32. National Research Council-National Academy of Sciences Publication No. 1146, 1964. Washington, DC. 4.

\begin{tabular}{|c|c|c|c|c|c|c|c|c|c|c|c|c|c|}
\hline Turnover & & & \multicolumn{3}{|c|}{ VLDL to LDL conversion } & \multicolumn{3}{|c|}{ VLDL not converted to LDL } & $\begin{array}{l}\text { LDL “direct" } \\
\text { synthesis }\end{array}$ & $\begin{array}{l}\text { \% VLDL not } \\
\text { converted } \\
\text { to } \mathrm{LDL}\end{array}$ & $\begin{array}{l}\text { Ratio synthetic rates } \\
\frac{\text { (LDL apoB) }}{\text { (VLDL apoB) }}\end{array}$ & $\begin{array}{l}{ }^{125} \mathrm{I} \\
\text { Urine } \\
\text { plasma }\end{array}$ & $\begin{array}{l}\text { Total Apo B } \\
\text { production* }\end{array}$ \\
\hline$m g / d$ & $m g / k g-d$ & $\begin{array}{l}m g / \\
F F M-d\end{array}$ & $m g / d$ & $m g / k g-d$ & $\begin{array}{l}m g / \\
F F M-d\end{array}$ & $m g / d$ & $m g / k g-d$ & $\begin{array}{l}m g / \\
F F M-d\end{array}$ & $m g / d$ & \% & & & $m g / d$ \\
\hline 1,358 & 7.9 & 13.0 & 1,376 & 8.0 & 13.2 & 892 & 5.2 & 8.6 & 10 & 39 & 0.60 & 0.40 & 2,293 \\
\hline 1,234 & 9.4 & 14.7 & 778 & 5.9 & 9.3 & 1,269 & 9.7 & 15.1 & 482 & 62 & 0.60 & 0.35 & 2,824 \\
\hline 1,446 & 11.1 & 16.6 & 1,425 & 11.0 & 16.4 & 2,068 & 15.9 & 23.8 & 26 & 59 & 0.41 & 0.35 & 3,537 \\
\hline 1,686 & 7.8 & 16.5 & 1,696 & 7.9 & 16.6 & 1,068 & 4.9 & 10.5 & 4 & 39 & 0.61 & 0.39 & 2,774 \\
\hline 1,063 & 11.2 & 15.9 & 1,036 & 10.9 & 15.5 & 559 & 5.9 & 8.3 & 35 & 35 & 0.67 & 0.37 & 1,695 \\
\hline 1,162 & 9.4 & 15.3 & 1,252 & 9.4 & 15.2 & 1,469 & 11.9 & 19.3 & 33 & 56 & 0.44 & 0.48 & 2,680 \\
\hline 1,266 & 10.0 & 18.2 & 1,165 & 9.1 & 16.7 & 949 & 7.5 & 13.6 & 101 & 45 & 0.60 & 0.54 & 2,338 \\
\hline 807 & 8.9 & 12.4 & 816 & 9.0 & 12.6 & 544 & 6.0 & 8.4 & 0 & 40 & 0.59 & & 1,360 \\
\hline 991 & 10.5 & 14.1 & 1,028 & 10.9 & 14.7 & 880 & 9.4 & 12.6 & 0 & 46 & 0.51 & 0.45 & 1,908 \\
\hline $1,224 \pm 87$ & $9.6 \pm 0.4$ & $15.2 \pm 0.6$ & $1,164 \pm 99$ & $9.1 \pm 0.6$ & $14.5 \pm 0.8$ & $1,078 \pm 159$ & $8.5 \pm 1.2$ & $13.4 \pm 1.8$ & $77 \pm 52$ & $47 \pm 3$ & $0.56 \pm 0.03$ & & $2,379 \pm 221$ \\
\hline- & - & - & 647 & 9.7 & 11.0 & 509 & 7.6 & 8.6 & - & 44 & - & - & - \\
\hline 753 & 11.1 & 13.0 & 654 & 9.6 & 11.3 & 625 & 9.2 & 10.8 & 121 & 49 & 0.59 & 0.31 & 1,526 \\
\hline 1,156 & 17.3 & 21.5 & 1,036 & 15.5 & 19.2 & 445 & 6.6 & 8.3 & 135 & 30 & 0.78 & 0.27 & 1,931 \\
\hline 694 & 13.9 & 15.8 & 610 & 12.2 & 13.8 & 372 & 7.4 & 8.4 & 101 & 38 & 0.78 & - & 1,248 \\
\hline 857 & 11.1 & 15.6 & 699 & 9.1 & 12.7 & 360 & 4.7 & 6.6 & 213 & 34 & 0.81 & 0.37 & 1,685 \\
\hline 545 & 8.4 & 9.5 & 533 & 8.2 & 9.3 & 480 & 7.4 & 8.4 & 17 & 47 & 0.54 & 0.33 & 1,049 \\
\hline 804 & 12.4 & 16.3 & 528 & 8.1 & 10.7 & 432 & 6.6 & 8.7 & 287 & 45 & 0.84 & 0.27 & 1,598 \\
\hline $802 \pm 83$ & $12.3 \pm 1.2$ & $15.3 \pm 1.6$ & $672 \pm 65$ & $10.3 \pm 1.0$ & $12.6 \pm 1.2$ & $460 \pm 34$ & $7.1 \pm 0.5$ & $8.5 \pm 0.5$ & $146 \pm 38$ & $41 \pm 3$ & $0.71 \pm 0.05$ & & $1,506 \pm 129$ \\
\hline$P<0.01$ & NS & NS & $P<0.001$ & NS & NS & $P<0.01$ & NS & $P<0.05$ & NS & $P=11$ & $P<0.05$ & & $P<0.001$ \\
\hline
\end{tabular}

